\title{
UPAYA PEMANFAATAN LIMBAH TERNAK BAGI PERTANIAN MENUJU DESA MANDIRI
}

\author{
Riana Rachmawati Dewi ${ }^{11}$, Kartika Hendra Titisari ${ }^{11}$, Anita Wijayanti ${ }^{1}$, Srie Juli Rachmawatie ${ }^{2)}$ \\ 1)Program Studi Akuntansi, Univesitas Islam Batik, Surakarta, Jawa Tengah, Indonesia \\ 2)Program Studi Agroteknologi, Universitas Islam Batik, Surakarta, Jawa Tengah, Indonesia \\ Corresponding author : Riana Rachmawati Dewi \\ E-mail : rianardewi1@gmail.com
}

\section{Diterima 12 November 2021, Direvisi 14 Desember 2021, Disetujui 14 Desember 2021}

\begin{abstract}
ABSTRAK
Desa yang mampu secara ekonomi mampu menghidupi wilayahnya merupakan harapan amanat UU Desa nomor 6 tahun 2014 yang dikenal Desa Mandiri. Pemanfaatan potensi desa di Desa Ngrawan sejak tahun 2012 sebagai desa Menari karena mengangkat tema budaya lokal. Masih banyaknya potensi yang belum digarap secara optimal terutama bidang pertanian dan peternakan yang menjadi sumber utama penghasilan masyarakat Desa. Tujuan kegiatan pengabdian ini adalah pemberdayaan masyarakat dalam memanfaatkan limbah ternak untuk pertanian sehingga mengurangi biaya pembelian pupuk. Mitra adalah tokoh masyarakat dan karang taruna sebanyak 7 orang. Metode yang dilakukan melalui sosialisasi, pelatihan dan pendampingan. Hasil dari program ini pupuk organik yang dapat dikembangkan oleh peternak sapi di desa dan dapat menjadi Desa eduwisata di Ngrawan dimana masyarakatnya semakin kreatif dalam pengelolaan potensi bidang pertanian dan peternakan untuk memelihara dan menjaga ketahanan pangan.
\end{abstract}

Kata kunci: potensi;lokal;peternakan, pertanian

\begin{abstract}
Villages that are economically capable of supporting their territory are the hope of the mandate of the Village Law number 6 of 2014 which is known as Independent Village. Utilization of village potential in Ngrawan Village since 2012 as a menari village because it raises the theme of local culture. There is still a lot of potential that has not been exploited optimally, especially in the fields of agriculture and animal husbandry which are the main sources of income for the village community. The purpose of this service activity is to empower the community in utilizing livestock waste for agriculture so as to reduce the cost of purchasing fertilizer. Partners are community leaders and youth organizations as many as 7 people. The method used is through socialization, training and mentoring. The results of this program are organic fertilizers that can be developed by cattle breeders in the village and can become an edutourism village in Ngrawan where the community is increasingly creative in managing the potential of agriculture and animal husbandry to maintain and maintain food security.
\end{abstract}

Keywords: potential; local; livestock, agriculture

\section{PENDAHULUAN}

Periode tahun 2009, slogan Bali Ndeso Mbangun Deso yang dijadikan semangat oleh Gubernur Jawa Tengah H. Bibit Waluyo agar masyarakat desa mau kembali untuk membangun daerahnya. Kekhawatiran tersebut dipicu adanya urbanisasi yang menyebabkan munculnya perbedaan pertumbuhan atau ketidakmerataan fasilitas-fasilitas dari pembangunan antara desa dan kota. Akibatnya, wilayah perkotaan menjadi magnet menarik bagi pendatang dalam mendapatkan pekerjaan baru. Urbanisasi secara ekonomi sejatinya merupakan suatu proses perubahan yang wajar dalam upaya meningkatkan kesejahteraan penduduk atau masyarakat (Harahap, 2013)
Pemerintah Indonesia melalui Kementerian Desa, Pembangunan daerah Tertinggal dan Transmigrasi pada tahun 2015 mempunyai mandat menjalankan NAWACITA yang ketiga yaitu Membangun Indonesia dari pinggiran dengan memperkuat daerah dan desa serta mengawal implementasi UU no 6 tahun 2014 tentang Desa (Rahmawati, 2015).

Hasil penelitian World Bank (2018) menyatakan bahwa urbanisasi ternyata mempunyai kemampuan untuk menurunkan tingkat kemiskinan yang dijelaskan dengan adanya peningkatan Produk Domestik Bruto (PDB) di negara China, India, Thailand, dan Vietnam. Di India setiap $1 \%$ pertumbuhan urbanisasi hanya mampu meningkatkan PDB per kapita $13 \%$. Hal tersebut berbeda dengan 
Indonesia dimana $1 \%$ pertumbuhan urbanisasi hanya mampu meningkatkan nilai PDB sebanyak $4 \%$. Hal tersebut mengindikasikan bahwa urbanisasi belum cukup mampu untuk memberikan tingkat kesejahteraan bagi pelakunya agar dapat keluar dari kemiskinan (Chen, Sui, Liu, Liu, \& Huang, 2019)

Wilayah perdesaan ternyata menjadi prioritas dari pemerintah setelah era reformasi, banyaknya dukungan pendanaan yang dikucurkan pemerintah di wilayah desa. UU Desa no 6 Tahun 2014 yang didalam pasalnya menyebutkan jumlah besaran dana yang dapat diberikan untuk membangun fasilitas desa sehingga masyarakat desa tidak merasa ada ketimpangan pembangunan dan dapat ikut berpartisipasi untuk membangun desa (Pandung \& Arida, 2018).

Dusun Tanon bagian dari Desa Ngrawan merupakan salah satu contoh desa di Jawa Tengah yang mulai tahun 2012 berupaya menjadi desa wisata. Desa yang terletak di lereng pegunungan Telomoyo Kabupaten Semarang terletak di daerah yang sejuk dan masih asri. Banyak terbentang sawah, tegalan, kebun sehingga pemandangan alamnya hijau dan menyejukkan mata.

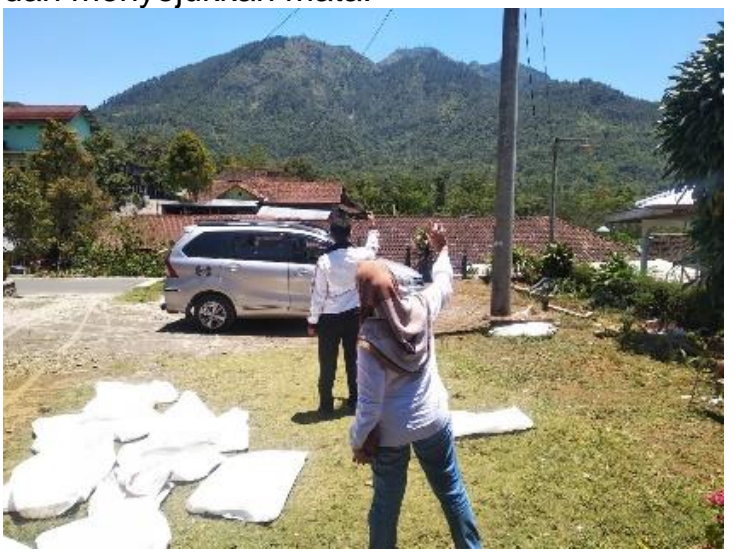

Gambar 1. Lokasi desa

Pemuda Desa bernama Sutrisno membuat ide untuk mengembangkan desa tersebut dengan pertunjukan tari khas daerah tersebut sehingga sampai sekarang lebih dikenal dengan Desa Menari.

Didesa Ngrawan masih banyak dijumpai persawahan dan peternakan yang merupakan milik perorangan. Hampir di setiap rumah penduduk mempunyai ternak sapi. Kandang ternak yang kurang bersih ditambah dengan perawatan ternak sapi yang cenderung kurang mengakibatkan munculnya bau yang kurang sedap. Bagi masyarakat desa hal tersebut sudah merupakan hal yang biasa, tetapi menjadi masalah saat Desa tersebut mulai membuka wilayahnya untuk wisata lokal (Tangkas \& Trihadiningrum, 2016).
Hal tersebut terjadi saat tim kegiatan pengabdian kepada masyarakat mengunjungi lokasi Desa Ngrawan pada 4 Januari 2021. Tim pengabdi melihat banyaknya potensi desa yang belum dikelola secara maksimal. Kelebihan yang ada didesa tersebut adalah budaya masyarakat setempat yang masih dikelola dengan baik, keinginan masyarakat untuk membangun desanya dengan potensi yang dimiliki, pemuda yang aktif dalam karang taruna (Astuti \& Issundari, 2016). Adanya perpustakaan yang dikelola oleh pemuda desa, seni tradisional yang sudah berjalan baik, dan menjadi desa binaan Astra.

Kelemahan yang dapat disampaikan adalah masih kurangnya pengetahuan dalam bidang pertanian, peternakan, pengolahan hasil pertanian, pengelolaan limbah, dan pengelolaan bidang ekonomi.

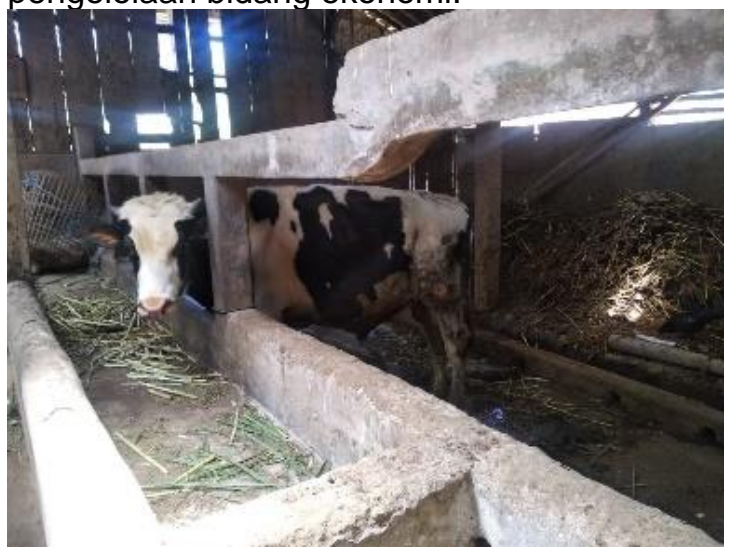

Gambar 2. Kandang ternak

Masyarakat desa mudah diajak bekerjasama untuk membangun desa menjadi kekuatan yang besar untuk dapat segera terealisasi. Pihak Desa sangat antusias untuk bekerjasama dalam bidang ekonomi dan nantinya dapat mengurangi ketergantungan kepada pemerintah karena desa mampu mengelola daerahnya untuk meningkatkan pendapatan (Yusmiono, Wisata, \& Batanghari, 2019).

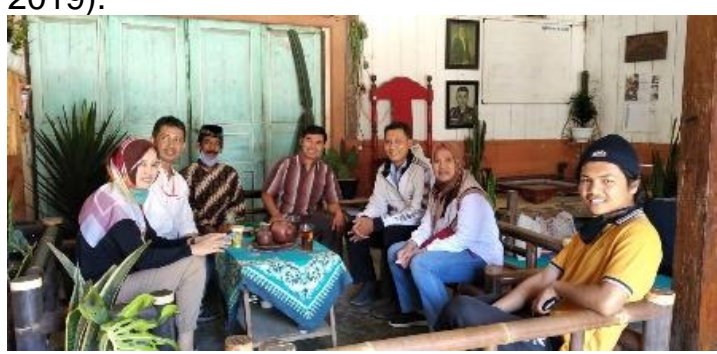

Gambar 3. Diskusi dengan tokoh desa dan ketua karang taruna

Masalah kandang ternak dan pengelolaan limbah ternak menjadi fokus dalam kegiatan pengabdian kepada masyarakat oleh tim pengabdi selama 2 (dua) bulan kegiatan pengabdian di bulan Februari sampai Maret 
2021. Ketua tim pengabdi pernah bekerjasama dengan mitra yaitu Balai Penelitian dan Diklat yang terletak di wilayah Cangkringan dalam mengolah limbah ternak menjadi pupuk organik di daerah pemukiman yang padat penduduk.

\section{METODE}

Kegiatan pengabdian yang dilakukan selama 2 (dua) bulan Februari dan Maret tahun 2021 di lokasi bapak Sutrisno sebagai lokasi untuk praktek pengolahan limbah ternak.

Bentuk kegiatan yang dilakukan oleh tim pengabdi, Bapak Sutrisno dan pengurus karang taruna yang setuju untuk bekerjasama menjalankan pengabdian kepada masyarakat adalah sebagai berikut :

Tabel 1. Tahapan kegiatan

\begin{tabular}{lll}
\hline Kegiatan & Tujuan & Luaran \\
\hline Sosialisasi & $\begin{array}{l}\text { Dilakukan } \\
\text { kepada } \\
\text { Bapak }\end{array}$ & $\begin{array}{l}\text { Jadwal } \\
\text { kegiatan }\end{array}$ \\
& $\begin{array}{l}\text { Sutrisno dan } \\
\text { pengurus }\end{array}$ & \\
& karang & \\
& taruna & \\
\hline Pelatihan & $\begin{array}{l}\text { Praktek } \\
\text { pengolahan }\end{array}$ & \\
& $\begin{array}{l}\text { Pupuk organik } \\
\text { limbah }\end{array}$ & \\
& ternak di & \\
& mitra tim & \\
\hline Perbaikan & Kangabdi & \\
kandang & sapi yang & Adanya \\
sapi & bersih dandang sapi \\
& tidak berbau & \\
\hline Evaluasi & Memastikan & Produk yang \\
& hasil & termanfaatkan \\
& pelatihan & \\
dilaksanakan & \\
\hline
\end{tabular}

Metode ini dilakukan oleh tim pengabdi, mitra, Bapak Sutrisno dan karang taruna secara bersama-sama sebanyak 7 (tujuh) orang. (Maruf, 2014) suatu aktivitas ekonomi dapat muncul dikarenakan daerah tersebut melakukan pengembangan potensinya. Tujuan kegiatan ini dilaksanakan adalah membantu masyarakat Desa dalam mengembangkan potensi wilayah melibatkan masyarakat setempat. Kegiatan ini dilaksanakan di desa Ngrawan Kecamatan Getasan Kabupaten Semarang.

\section{HASIL DAN PEMBAHASAN}

Dari tahapan kegiatan yang direncanakan maka selanjutnya dijelaskan hasil dari pelaksanaan kegiatan tersebut.
Sosialisasi awal dilakukan pada 5 Februari 2021 langsung setelah tim pengabdi melakukan kunjungan langsung ke lokasi kegiatan di Desa Ngrawan.

Sosialisasi awal sebagai edukasi pentingnya udara yang bersih dan tidak berbau kotoran binatang.

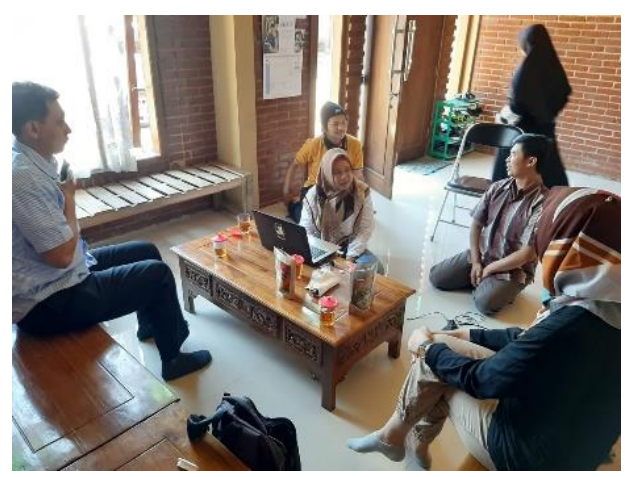

Gambar 4. Sosialisasi

Sosialisasi atas pengelolaan limbah ternak menjadi pupuk organik dan kandang sapi yang sehat dan mudah untuk dibersihkan agar kotorannya tidak berbau.

2. Pelatihan

Setelah sosialisasi dilakukan kepada tokoh desa dan pengurus karang taruna dan hasilnya disetujui untuk dilakukan pelatihan mengelola limbah ternak dan model kandang sapi yang sehat. Pada tanggal 18 19 Februari dilakukan pelatihan pembuatan pupuk organik.

Kegiatan pelatihan langsung dilakukan pada lokasi mitra Balai Pelatihan dan Diklat yang dipandu langsung oleh Ir. Gembong Danudiningrat (pemilik sekaligus pengelola tempat tersebut). Pelatihan dilakukan bersamaan dengan kegiatan praktek kerja mahasiswa Fakultas Pertanian.

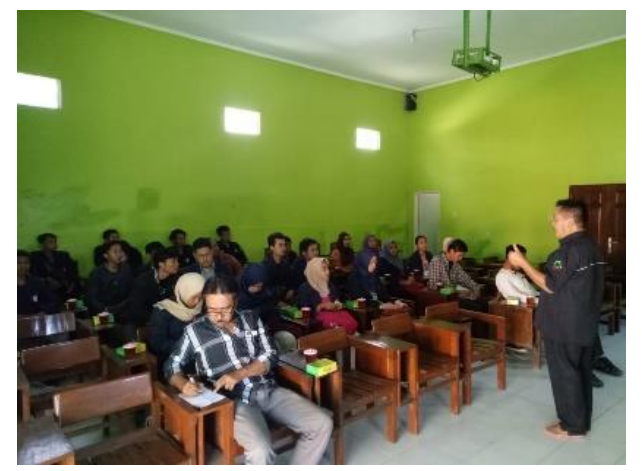

Gambar 5. Penjelasan dari mitra

Selanjutnya , dilakukan pelatihan pembuatan pupuk organik. 


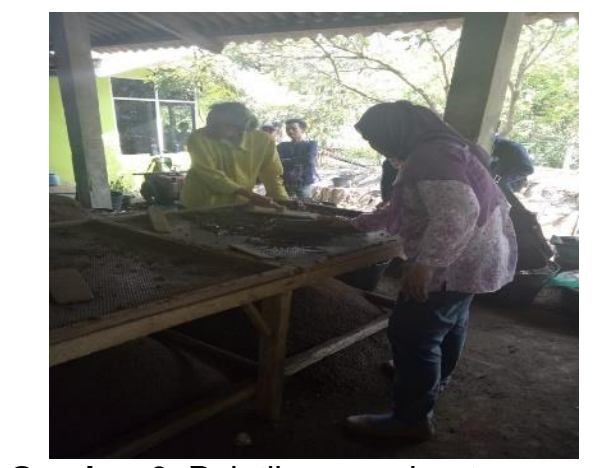

Gambar 6. Pelatihan pembuatan pupuk organik

Tahapan pembuatan pupuk organik adalah sebagai berikut (Juli Rachmawatie, Rachmawati Dewi, \& Rosana Dewi, 2019) :

a. Limbah ternak padat dan limbah pertanian dicampurkan jadi satu dalam ruang terbuka yang sirkulasi udara bebas keluar masuk tetapi tidak boleh terkena sinar matahari selama 1 minggu

b. Selanjutnya dengan dibantu bakteri yang disemprotkan pada limbah tersebut sebagai bahan pengurai, setiap lapisan disemprot dengan bakteri. Setelah semuanya merata maka ditutup dengan terpal selama \pm 7 hari.

c. Setelah mulai terurai dan tidak terasa panas, maka pupuk organik tersebut diayak agar lembut dan gampang menyerap kedalam tanah.

d. Proses akhir yang dilakukan adalah pengepakan.

Setelah menerima penjelasan dan praktek pembuatan pupuk organik dari mitra, selanjutnya tim dari Desa Ngrawan mulai melihat kandang sapi yang dikelola dengan baik.

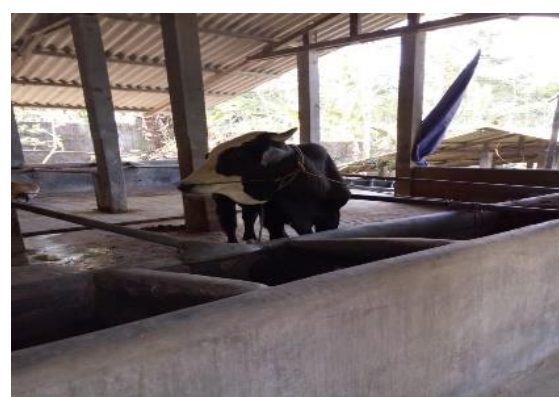

Gambar 7. Kandang sapi yang dikelola baik

Kandang sapi yang baik adalah yang terbuka dan cukup sinar matahari. Untuk bagian bawah sengaja dibuat agak miring agar urine mudah untuk dipisahkan dari limbah padatnya (Tangkas \& Trihadiningrum, 2016). Urine sapi juga dapat dibuat sebagai pupuk sendiri dan tidak digabungkan dengan limbah padatnya.

Tim pengabdi melakukan pendampingan di Desa Ngrawan dengan ujicoba rumah Bapak Sutrisno yang memiliki ternak sapi. Uji coba dilakukan dalam bulan Maret 2021.

Hasil ujicoba untuk pengolahan pupuk organik dapat dilihat pada gambar 8 .

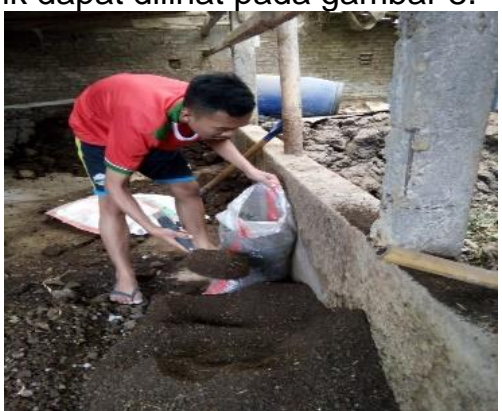

Gambar 8. Hasil pengolahan pupuk organik

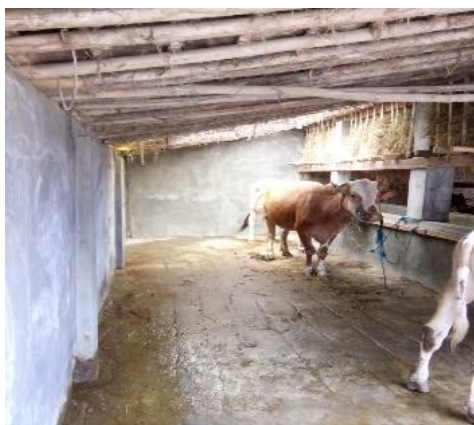

Gambar 9. Kandang sapi yang sudah diperbaiki

Pada gambar 9 dapat diperlihatkan bahwa kandang sapi Bapak Sutrisno sudah diperbaiki sesuai dengan arahan hasil pelatihan.

\section{SIMPULAN DAN SARAN}

Upaya Desa Ngrawan untuk mewujudkan Desa Mandiri secara ekonomi membutuhkan beberapa tahapan kegiatan yang berkelanjutan (Kholil \& Khoirunnisa, 2018) . Setelah mengelola budaya setempat dan menjadi binaan Astra, tahapan selanjutnya adalah mengelola bidang pertanian dan peternakan. Pada tahapan ini mengelola limbah ternak agar bermanfaat secara ekonomi dan lingkungan. Desa Ngrawan mulai berbenah dengan melibatkan pemuda desa mengelola limbah ternak dari hasil pelatihan. Partisipasi masyarakat yang besar untuk mendukung keberhasilan kegiatan sebagai motivasi utama desa dapat berkembang dan maju (Kurniawan, Anita, \& Nisa, 2020)

\section{DAFTAR RUJUKAN}

Astuti, M., \& Issundari, S. (2016). Desa wisata sebagai aset soft power Indonesia. 
Masyarakat, Kebudayaan Dan Politik, 29(2),

64.

https://doi.org/10.20473/mkp.v29i22016.6 4-74

Chen, M., Sui, Y., Liu, W., Liu, H., \& Huang, Y. (2019). Urbanization patterns and poverty reduction: A new perspective to explore the countries along the Belt and Road. Habitat International. https://doi.org/10.1016/j.habitatint.2018.1 2.001

Harahap, F. R. (2013). DAMPAK URBANISASI BAGI PERKEMBANGAN KOTA DI INDONESIA. Society. https://doi.org/10.33019/society.v1i1.40

Juli Rachmawatie, S., Rachmawati Dewi, R., \& Rosana Dewi, T. (2019). ALIH TEKNOLOGI PENGELOLAAN LIMBAH TERNAK BAGI UMKM MIKRO PETERNAK SAPI. Jurnal Kewirausahaan Dan Bisnis. https://doi.org/10.20961/jkb.v23i12.27494

Kholil, A. Y., \& Khoirunnisa, N. (2018). Strategi Pengembangan Desa Wisata Gubugklakah. Optima, 2(1), 27. https://doi.org/10.33366/opt.v2i1.899

Kurniawan, K., Anita, E. D., \& Nisa, S. U. (2020). BIMBINGAN KELOMPOK MASYARAKAT DESA MENURAN KECAMATAN BAKI DALAM PEMBANGUNAN DAN PENGEMBANGAN POTENSI WISATA DI SUNGAI BAKI. JURNAL CEMERLANG: Pengabdian Pada Masyarakat. https://doi.org/10.31540/jpm.v2i2.605

Maruf, et all. (2014). Pengukuran Daya Saing Klaster Batik, Konveksi. BENEFIT Jurnal Manajemen Dan Bisnis, (9), 1-16. Retrieved from ournals.ums.ac.id/index.php/benefit/articl e/view/4172

Pandung, M. A., \& Arida, I. N. S. (2018). Praktik Ekowisata Di Kampung Waerebo Kabupaten Manggarai, Provinsi Nusa Tenggara Timur. JURNAL DESTINASI PARIWISATA.

https://doi.org/10.24843/jdepar.2017.v05.i $01 . p 15$

Rahmawati, H. I. (2015). Analisis Kesiapan Desa dalam Implementasi Penerapan UU Nomor 6 Tahun 2014 tentang Desa (Studi pada Delapan Desa di Kabupaten Sleman). The 2nd University Research Coloquium.

Tangkas, G. P., \& Trihadiningrum, Y. (2016). Kajian Pengelolaan Limbah Padat Peternakan Sapi Simantri Berbasis 2R (Reduce dan Recycle) di Kecamatan Seririt, Kabupaten Buleleng. Jurnal Teknik ITS.

https://doi.org/10.12962/j23373539.v5i2.1
7071

Yusmiono, B. A., Wisata, O., \& Batanghari, S. (2019). Analisis Potensi Pengembangan Objek Wisata Sungai Batanghari. 90-99. 